\title{
Arbor
}

\section{La industria aeroespacial: un modelo de integración para la industria de defensa}

\author{
Santiago San Antonio Copero
}

Arbor CLXXI, 674 (Febrero 2002), 419-456 pp.

En este artículo se explican las causas que han propiciado la integración de las industrias aeronáuticas:

- En Estados Unidos para posicionarse en el mundo como líder indiscutible y consolidar su mercado dentro y fuera de sus fronteras.

- En Europa, y como consecuencia de lo anterior, para sobrevivir al gigante norteamericano e intentar no verse reducida a un papel secundario.

En el artículo se hace una clara exposición de cómo se ha realizado el citado proceso de integración en Estados Unidos y en Europa, donde el proceso ha sido lógicamente más dificil, pues ha tenido que vencer grandes reticencias soberanistas, legales y administrativas.

La parte más detallada corresponde al EADS (Sociedad Europea Aeronáutica Espacial y de Defensa), pues es donde está integrada CASA (Construcciones Aeronáuticas), la empresa española más importantes en el sector aeroespacial.

\section{Introducción}

Durante la Segunda Guerra Mundial, y especialmente a partir de la misma, empezó a tomar una importancia cada vez mas acusada y con un ingrediente de aceleración, el concepto del poder aéreo. Sus característi- 
cas peculiares le constituían en una fuerza intrínsecamente estratégica y en un arma fundamentalmente ofensiva, con la importancia que supone su dominio de la cuarta dimensión: el tiempo.

En la década de los 40 del siglo pasado está el embrión del programa espacial norteamericano (con Wernher von Braun y su grupo de científicos) con el tremendo desarrollo a que ha dado lugar la inauguración de la era nuclear (Los Alamos, Robert Openheimer) y el dominio de la barrera del sonido.

La supremacía del poder aéreo en la concepción global estratégica fue poco a poco ganando partidas con hombres como Douhet y Seversky, imponiéndose firmemente una doctrina aeroespacial hasta entonces denostada.

Con esta semilla se ha producido un proceso de aceleración en el ámbito aerospacial con necesidades cada vez más exigentes, tanto desde el punto de vista militar como civil y que ha dado lugar a una gigantesca infraestructura del transporte aéreo convencional y a una reafirmación del poder aeroespacial como elemento absolutamente imprescindible y decisorio en cualquier contienda.

Estas necesidades crecientes han propiciado un crecimiento y un avance tecnológico de la industria aeroespacial -en los ámbitos civil y de la defensa- que la han constituido en pionera y avanzada del resto de las industrias de defensa.

Es por todo ello que, a partir del fin del bipolarismo a raíz de la caída del muro de Berlín y el profundo cambio en el concepto global estratégico de los años posteriores, la industria de defensa se viera directamente afectada y, en especial, la aeroespacial que, por ser la más sensible y ver amenazada su situación de preeminencia y su crecimiento futuro, fue la primera en reaccionar, dando lugar a los rápidos cambios de los que aún estamos siendo testigos.

\section{Antecedentes}

Los antecedentes de este proceso comienzan a manifestarse a partir de la década de los 80, en la carrera por el dominio del espacio exterior entre las dos superpotencias, que dio lugar en los Estados Unidos al programa denominado "Iniciativa de Defensa Estratégica» (SDI), con el objeto de controlar desde el espacio la utilización del armamento de destrucción masiva -especialmente el nuclear-y de establecer también, desde el espacio, una defensa muy temprana y eficaz. Ello condujo a una carrera tecnológica que, por parte de la Unión So- 
viética, se convirtió en desesperada, forzando al límite sus recursos económicos, utilizados masivamente para mantener esa competición y empobreciendo enormemente su economía en áreas vitales, hasta el punto de hacer imposible la continuidad de un ritmo ya muy desfasado y sin posibilidades de éxito. Este hecho, unido sin duda a otras consideraciones de carácter doctrinal e ideológico, pero que puso de manifiesto su debilidad y error conceptual, contribuyó en gran medida a la quiebra de las estructuras política, social y económica de este país y a la profunda transformación de alcance mundial que, todavía, no se ha sedimentado.

Paradójicamente, aquí se produjo la falla, el acelerado avance tecnológico de la industria aeroespacial que precipitó -casi por colapso- el desmoronamiento de la Unión Soviética, hizo desaparecer el bipolarismo de la guerra fría entre las dos superpotencias y, con ello, la desaparición de la amenaza nuclear como principal elemento de confrontación y disuasión. La consecuencia directa e inmediata fue un cambio de orientación en el concepto estratégico global y, en especial, en el seno de la Alianza Atlántica, hacia otro tipo de amenazas potenciales, de carácter multidireccional y regional que demandaban, para hacerlas frente, medios más convencionales.

Paralelamente, y como consecuencia de ese acelerado avance tecnológico, se ha producido una verdadera explosión en el mundo de la electrónica, de las comunicaciones y de la información, con la peculiaridad de que su desarrollo e impulso ha tenido lugar en el mundo comercial sobrepasando por primera vez, en tecnología, la industria civil a la industria de defensa. El aprovechamiento militar de dichas tecnologías ha sido prácticamente inmediato y en progresión creciente por tres razones: imposibilidad de su desarrollo con la velocidad de la industria civil, su cada vez mayor perfección y fiabilidad y, muy en especial, su inmediata disponibilidad y mucho menor coste; la consecuencia inmediata de la utilización de componentes comerciales (COTS), es una disminución en el tiempo de obtención de los sistemas y una reducción de costes.

Por otra parte, la revisión del concepto global estratégico y el análisis de las nuevas amenazas ha dado lugar en los Estados Unidos a la llamada «Revolution in Military Affairs» (RMA) -en su denominación originalbasada en la capacidad de procesar y controlar la enorme cantidad de información (datos) proporcionada por los modernos sistemas y de distribuirla a través de comunicaciones seguras rápidas y fiables; este concepto -RMA- supone la integración de los Sistemas de Mando, Control, Comunicaciones, Ordenadores, Inteligencia, Vigilancia y Reconocimiento (Command, Control, Communications, Computers, Intelligence, Survei- 
llance and Reconnaisance-C4ISR) con las armas de precisión de largo alcance en un único Sistema de Sistemas para el total dominio del Teatro de Operaciones y el desarrollo de la batalla; el conocimiento y el control de la información se ha hecho indispensable para todo tipo de misiones ya sean en paz o en guerra, logísticas o de combate. Todo esto lleva implícito como componente necesario, un sistema preciso, seguro, de posicionamiento en tiempo real, con lo cual el espacio y el ciberespacio -y su control- se convierten en las dos nuevas dimensiones, junto con tierra, mar y aire para el desarrollo de las operaciones.

La aproximación a la industria civil y su interacción con la misma, con la utilización creciente de elementos comerciales, ha hecho, por tanto, surgir la necesidad de ir abandonando el rígido cumplimiento de las especificaciones militares y de comenzar a utilizar, cada vez en mayor medida, criterios industriales lo que, a su vez, ha dado lugar a la necesidad de flexibilizar los criterios de adquisición de los sistemas de armas y los métodos de gestión.

En este mismo período de tiempo y como consecuencia directa de la drástica disminución de la amenaza y el cambio del concepto global estratégico, los presupuestos de defensa experimentaron una vertiginosa caída, especialmente a partir de los años 1988/89 y prácticamente hasta el año 2000. En ese período de tiempo y tomando de referencia el año 1998, en Estados Unidos la reducción llegó al 30\% y la media de los países europeos hasta el $20 \%$. La tasa de decrecimiento, no obstante haber frenado apreciablemente en los últimos años, no ha invertido aún su tendencia.

Paradójicamente, el recorte de los presupuestos de defensa ha coincidido con los mayores avances tecnológicos que ha dado lugar, a su vez, a un incremento cada vez mayor en los costes de desarrollo de los nuevos sistemas de armas, cada vez con mayores capacidades y de una gran complejidad.

Es decir, nos encontramos ante la coyuntura de una sostenida reducción en los presupuestos para la adquisición de nuevos sistemas de armas y equipos, con un incremento sostenido de los costes de desarrollo; ello nos lleva a una reducción del número de programas y del tamaño de los mismos, que se evidencia en especial en la industria aeroespacial de defensa en el número y entidad de programas de aviones de combate.

Todos estos factores han propiciado dos reacciones necesarias e inevitables en la industria de defensa, para su propia supervivencia y para poder hacer frente a la nueva y cambiante situación: reducción de costes y reestructuración.

La reducción de costes ha sido la respuesta consecuente de la industria a la reducción de los gastos de defensa pero el recorte y el ajuste en 
La industria aeroespacial: un modelo...

los costes de operación (overheads), necesita ir de la mano de una reestructuración racional para conseguir la dimensión adecuada, encaminada en última instancia a reducir los costes fijos asociados a un exceso de capacidad.

Este proceso de reestructuración ha tenido lugar de forma muy peculiar y muy rápidamente en Estados Unidos, reaccionando ante una menor y diferente demanda nacional, consolidando su proceso antes que Europa y saliendo de forma agresiva al mercado internacional, dada la enorme importancia de las exportaciones para la industria americana. El intento de incrementar su penetración y presencia en los mercados europeos se vio, no obstante, frenado considerablemente por la conciencia de la clara amenaza que representaba y la reacción casi precipitada de la propia industria.

La reestructuración de la industria de defensa europea ha sido más larga y complicada por la evidente compartimentación y fragmentación de los diversos mercados nacionales y las implicaciones políticas, económicas e industriales y legales asociadas. Ha tenido lugar en dos fases en cierto modo diferenciadas: en una primera fase ha tenido lugar un proceso interno nacional de consolidación de la industria de defensa, en especial en los principales países suministradores de armamento y, en una segunda fase, realmente acelerada, un proceso de reestructuración transnacional con unos primeros pasos muy importantes, pero aún en evolución y con los problemas asociados a la consecución de un espacio común europeo.

En ambos continentes la industria aeroespacial y de electrónica de defensa han sido las pioneras y el modelo en el proceso de integración y reestructuración. Como se ha analizado anteriormente, su papel dominante viene dado por su gran contenido tecnológico, siempre de vanguardia y por desarrollar los sistemas clave y de mayor eficacia, para la ejecución de las operaciones militares en la guerra moderna y para subvenir a las necesidades crecientes en el ámbito civil aeroespacial. Este es el motivo por el que, el análisis de los procesos americano y europeo, se centrará en este tipo de industrias.

\section{El proceso de reestructuración del sector aeroespacial en los Estados Unidos}

El proceso de reestructuración de la industria americana tuvo lugar muy rápidamente una vez detectada la necesidad a la luz de las circunstancias anteriormente consideradas. La velocidad de los ajustes y su ra- 
cionalidad se vieron ambas favorecidas por los siguientes factores:

- Estados Unidos es un solo país sin problemas de soberanía en relación con otros países involucrados en este proceso como ocurre en Europa.

- Dispone de una estructura legal única y común en todo su ámbito; Normas industriales y comerciales, procedimientos administrativos, etc., son por lo tanto comunes.

- Es la primera potencia mundial desde el punto de vista industrial y de la defensa, con voluntad firme y decidida de mantener esa situación de preeminencia.

- La reestructuración se reducía a una sola fase de consolidación de la propia industria nacional.

Independientemente de que, dados estos factores, este proceso estuviese fundamentado en la necesidad de adaptación a la coyuntura económica, se vio además favorecido e impulsado por el propio gobierno que dirigió y facilitó el camino para ello. En la ya famosa «Ultima Cena» que tuvo lugar en 1993, el Secretario de Defensa William Perry dijo claramente a los Presidentes de los grupos industriales más importantes, que el número de compañías del sector de defensa tendría que reducirse considerablemente y con gran rapidez, para poder hacer frente a la cambiante situación y para adaptarse a unos presupuestos de defensa decrecientes y considerablemente reducidos en el futuro.

Para hacer efectivas estas directrices, el gobierno decidió no aplicar la ley «anti-trust» y apoyó la consolidación de los acuerdos con una financiación cercana a un billón y medio de dólares; esta cifra representó, aproximadamente, la mitad de los costes incurridos por las empresas en el proceso, que finalizó en su totalidad a finales de 1997 consolidando, básicamente cuatro grandes empresas, Boeing, Lockheed Martin, Raytheon y Northrop Grumman de las cuales, las dos primeras eran verdaderas gigantes (ver Anexo $\mathrm{n}^{0}$ 1).

Finalizada la consolidación para hacer frente a las necesidades de su enorme mercado interior de defensa, en el paso siguiente se produjo una reorientación para afirmarse y adaptarse a los mercados internacionales con el decidido y positivo apoyo de su propia Administración -La Administración Clinton-, con el propósito de mantener y a ser posible aumentar su hegemonía con el mayor grado de monopolio en los sectores vitales de la industria de defensa de más alta tecnología.

Este segundo paso llegó quizá un poco tarde; en 1998 ya en Europa se había percibido claramente la amenaza del gigante americano y a partir, principalmente, de 1997 comenzó el proceso acelerado de la reestructuración europeo. 


\section{El proceso de reestructuración en el sector aeroespacial en Europa}

Ciertamente, el grado de complicación y dificultad para la reestructuración de la industria europea de defensa, es muy superior al de Estados Unidos. No existe, para empezar, un espacio común europeo; la diversidad de legislaciones, procedimientos administrativos, estructura social, diversidad de objetivos políticos y económicos, unido todo a un acendrado sentido del principio de soberanía, no cabe duda que son factores que, si en el caso de Estado Unidos, simplemente no estaban presentes, en el caso de Europa han opuesto un claro freno a este proceso y es evidente que, pese a lo conseguido hasta la fecha, quedan aún muchas incógnitas que despejar durante un largo futuro. Hay sin embargo un factor muy positivo y determinante en toda la Unión Europea: la decidida.voluntad política de ir consolidando espacios comunes y la potencia industrial del libre mercado para transformarse y adaptarse al mismo.

Con estos ingredientes el proceso europeo ha experimentado, principalmente desde finales de 1997, una sucesiva y rápida realimentación entre la voluntad política -plasmada en directrices a la industria- y la iniciativa de las empresas del sector que ha concluido en un claro liderazgo de las mismas que, saltando barreras transnacionales, han tomado la iniciativa para contrarrestar al peligro y adaptarse a la situación al margen, a veces, de las consideraciones políticas.

En un breve repaso histórico, el proceso europeo podemos dividirlo en tres fases en cierto modo diferenciadas, aunque con un amplio solape entre ellas:

- Un primera fase de consolidación de la industria nacional que arranca hacia 1950 y se extiende hasta los años 90 .

- Una segunda fase en la que empiezan a surgir una serie de sociedades conjuntas ("joint ventures") con un período muy activo entre 1990 y 1997, pero que aún continúa en forma importante.

- Y una fase de integración transnacional en la que los líderes de las diversas industrias nacionales ("National Champions") traspasan las fronteras en verdaderas fusiones ("mergers").

\subsection{Fase de consolidación de la industria nacional}

Tiene sus antecedentes remotos entre los años 1950 y principios de los 70. Tomando como ejemplo Francia, Alemania, el Reino Unido y Es- 
paña, de 30 compañías del sector aeroespacial, existentes en 1950, sólo quedaban 12 a principios de los 70, tras una serie de fusiones. En España supuso la integración en CASA, de Elizalde, Enmasa, Hispano Aviación y Aisa.

En el año 1990 -en los países mencionados-, el número de empresas se había reducido a 10 y el panorama, muy simplificado, en el resto de los sectores era el siguiente: Fabricantes de Helicópteros, 4; de Misiles, 8; Espacio, 14 y Electrónica de Defensa, 11.

En este período, la industria de defensa europea tenía un acendrado carácter nacional; los gobiernos consideraban a sus industrias de defensa como activos muy importantes de su propia soberanía, de tal forma que casi hasta finales de los años 90 , BAe ha sido la única compañía privada en Europa; el resto han sido, propiedad del Estado (Aerospatiale, CASA), o parte de compañías de gran tamaño (DASA, Saab), o ambas cosas (caso de Alenia). En todos los casos se produce un claro desenfoque en su estrategia, al estar ésta influida por factores políticos o por intereses distintos de la compañía madre, en vez de por la verdadera racionalidad comercial. En este contexto Italia y España han seguido -ya en los últimos años, posteriores a este período- un acelerado proceso de privatizaciones, como requisito necesario y previo para la integración transnacional, mientras que Francia ha sido y continúa siendo la más reacia a renunciar al control estatal.

Paralelamente a este proceso de consolidación, a principios de los años 50 y hasta finales de los 70, tienen lugar una larga serie de programas de cooperación internacional, la cual normalmente terminaba con la finalización del programa, pero que empezó a generar una tradición y unos lazos cada vez mas fuertes transnacionales para la ejecución de determinados proyectos, en especial relativos a los sectores aeroespacial y de electrónica. De los aproximadamente 60 programas de defensa originados en este período, 40 correspondían al sector aerospacial con un grado variable de cooperación internacional. Este tipo de programas carecían de una estructura común y se reducían a un simple reparto de tareas en las que cada socio era responsable de efectuar unos trabajos definidos de desarrollo y producción; ejemplos característicos de la industria aeroespacial son los programas «Transall» y «Jaguar»,

En un período posterior, este tipo de proyectos transnacionales se ha ido perfeccionando, partiendo de las mismas bases de reparto de tareas definidas (work sharing), de desarrollo y producción, pero ya con la estructura común de una organización conjunta, subsidiaria para la gestión del programa, comercialización, postventa, etc. Esta organización subsidiaria se constituye en el único interlocutor con los clientes y suele 
gozar del status legal de uno de los países participantes en el programa, o bien se constituye en un denominado Grupo de Interés Económico (GIE). Ejemplos más representativos son los relativos a los programas «Tornado» $\mathrm{y}$ «Eurofighter GmbH» en cuanto a organizaciones comunes subsidiarias y los programas «Euromissile» $\mathrm{y}$ «Airbus» en cuanto a GIE's.

No cabe duda que este tipo de proyectos ha representado un paso adelante en la formación de una cultura de cooperación internacional, racionalizando mas los procesos, consiguiendo mayores cotas de producción y ampliando el mercado, así como proporcionando una transferencia de tecnología entre países, contribuyendo con todo ello a la propia consolidación de las industrias nacionales. La racionalización de los procesos productivos necesitaba, no obstante, un empujón más ya que, como consecuencia de dicho sistema (en el que cada participante buscaba a toda costa adquirir capacidad y tecnología), se producían evidentes duplicidades y sobrecapacidad (puede ponerse como ejemplo el programa «Eurofighter» con nada menos que cuatro cadenas de montaje final, una por cada país). Se produce al mismo tiempo un excesivo alargamiento de los programas, debido a colisiones de intereses, dificultades de coordinación y dilaciones en los acuerdos. Y, adicionalmente, debido principalmente a esto último y a la complejidad de la organización se produce un importante incremento en los costes de gestión y administración de los programas.

\subsection{La aparición de las Sociedades Conjuntas («Joint Ventures»)}

A partir, por tanto, de los inicios de los 90 empiezan a surgir una serie de organizaciones más avanzadas, por esa necesidad de abordar con más racionalidad y con un mayor alcance temporal todos los programas de un determinado sector, tanto de carácter civil como militar. Son el antecedente inmediato a las posteriores integraciones entre las industrias líderes nacionales («National Champions»). Son las denominadas Sociedades Conjuntas o «Joint Ventures» en la terminología internacional más conocida y prácticamente aceptada; suelen tomar la forma de compañías de holding en la que cada participante lleva a cabo sus actividades de acuerdo con la ley de su propio país, pero esas actividades contribuyen al objetivo común del «holding» creado a dichos efectos y sujeto a la ley de uno de los países participantes o, incluso, de otro país diferente. Queda de este modo salvaguardada la identidad nacional de cada uno de los componentes del holding, un atavismo que, aún ahora, está siendo difícil de erradicar y que, en última instancia existen ciertas dudas en cuanto a que no haya que preservar. 
No hay que olvidar que este tipo de Sociedades Conjuntas estaban formadas por divisiones o filiales de las grandes compañías madre que siempre las han considerado como miembros de la propia familia y que, en la mayoría de los casos, siempre han prevalecido los intereses nacionales y estratégicos de aquellas en el reparto de tareas y responsabilidades.

Ejemplos de este tipo de compañías de Joint Venture se muestran en el Anexo n. ${ }^{\circ} 2$.

El verdadero avance de este tipo de organizaciones permanentes (más perfeccionadas serán muy beneficiosas en el futuro), consiste en la gestión única para la coordinación de las actividades del mercado, financiación, exportaciones y, principalmente, formulación de la estrategia del holding. Ha constituido, evidentemente un paso más en la racionalización industrial pero que a pesar de todo, chocaba en numerosas ocasiones contra intereses nacionales arraigados en el principio de soberanía. Es decir, el renunciar a ciertas capacidades tecnológicas y llegar a una verdadera especialización (la creación de verdaderos centros de excelencia), chocaba contra los intereses soberanos de las naciones por razones -aducidas- de seguridad nacional e incluso de las propias empresas madres por razones de competitividad en los diferentes mercados en otros sectores.

\subsection{La integración transnacional}

Sería utópico pensar que con la culminación de esta última fase de la fusión de algunas de las compañías líderes («National Champions») nacionales, en verdaderas compañías internacionales de magnitud muy superior, la verdadera racionalización industrial iba a tener lugar como un corolario. Evidentemente, la mera fusión por sí sola no evita la duplicidad de capacidades y tecnologías; dado el poder normativo de los gobiernos, la industria de defensa no es totalmente libre en cuanto al reparto de capacidades, ni en cuanto a la organización del trabajo y consideraciones de sensibilidad nacional van a seguir prevaleciendo en muchas ocasiones. El libre juego del mercado, por sí solo, puede llevar a la práctica desaparición de sectores enteros de la industria de defensa en países tecnológicamente peor dotados, o a situaciones cercanas al monopolio y, a no dudar, ese poder normativo de los gobiernos será utilizado directamente para evitarlo.

No obstante, esta elevación del nivel de integración a las industrias líderes propiciado por la experiencia internacional adquirida (Joint Ventures) en la etapa anterior, ha sido un paso absolutamente necesario 
La industria aeroespacial: un modelo...

para la propia supervivencia de la industria europea. Solamente de este modo se hace posible la necesaria disminución de los enormes gastos de operación («overheads») debidos a la complejidad de los entramados internacionales de cooperación, así como también la realización de economías de escala en la comercialización, centralización de compras, soporte logístico, etc.

Por otra parte, un nuevo aspecto a considerar en la industria aeroespacial y de electrónica de defensa, es el de la cada vez mayor importancia del mercado comercial. En el sector de electrónica de defensa, por la creciente utilización de sus tecnologías para aplicaciones en la vida civil, dada su naturaleza intrínseca de doble uso y porque a partir de un punto en el tiempo, los productos comerciales han tomado la iniciativa, llegando a desarrollos rapidísimos y con un nivel tecnológico que los hace aptos para su utilización cada vez mayor en los programas de defensa. Y en el sector aerospacial por el fuerte y sostenido crecimiento de la aviación civil, impulsado por una demanda cada vez mayor del mercado comercial.

El predominio cada vez mas acusado de este mercado, ha traído como consecuencia un cambio, no sólo en la estrategia de las empresas, sino en su propia cultura de mercado. Los criterios comerciales han comenzado a prevalecer sobre los de carácter político e incluso tecnológico, polarizando a las compañías hacia la eficacia y obtención del máximo beneficio, llevándolas hacia una paulatina privatización; el valor del accionista («Shareholder value») se había convertido en la ley del mercado. El obligado incremento en la productividad, el necesario acceso a mercados más amplios para poder cumplir dichos objetivos, unido todo a una fuerte competencia del otro lado del Atlántico, ha sido el cambio que ha llevado a la verdadera integración transnacional.

\subsubsection{El despegue hacia la integración}

El proceso estaba inevitablemente en marcha; a partir de mediados de los años 90 la amenaza de la rápida reestructuración aerospacial y de electrónica de defensa en Estados Unidos había hecho sonar la alarma tanto en los círculos industriales, como en los políticos: América estaba equipada para hacer frente a las nuevas exigencias del mercado doméstico e internacional y dejar a la industria europea reducida a un mero papel subsidiario obligándola, para sobrevivir, a alianzas muy desfavorables.

El detonante final tuvo lugar el 1 de Agosto de 1997 con la absorción oficial de McDonnell Douglas por Boeing; se había creado un gigante sin precedentes en el mundo aeroespacial. La integración de las actividades 
de todos los programas y tecnología de defensa de McDonnell Douglas con los del líder mundial en el desarrollo y producción de aviones comerciales había producido no sólo las adecuadas y necesarias sinergias, sino el equilibrio en los ciclos de los dos mercados, el militar y el civil, contrapuestos por naturaleza y, por tanto, complementarios. La amenaza se cernía principalmente sobre Airbus, el único competidor en el mercado mundial de la aviación comercial y la «niña de los ojos» de cuatro naciones, Francia, Reino Unido, Alemania y España, cuyos gobiernos habían hecho grandes inversiones, apostando por una presencia muy importante en el mercado mundial.

Es decir, confluían, casi al mismo tiempo, tres factores que impulsaron especialmente a los sectores aerospacial y de electrónica de defensa para la integración: la carrera para encontrar la masa crítica para poder hacer frente a los gigantes americanos $\mathrm{y}$, poder competir en el mercado internacional; la voluntad política de los gobiernos de mantener su industria de defensa empujando a los líderes nacionales de la misma a dar el paso definitivo para la verdadera consolidación de una industria europea y por último y especialmente importante, el impulso y la voluntad de toda la Unión Europea de conseguir una dimensión político-militar.

Aunque ya estaba implícito en el Tratado de Maastrich, es el Tratado de Amsterdam, acordado en el plano político en Junio de 1997 y firmado el 2 de Octubre de dicho año (y finalmente vigente desde el 1 de Mayo de 1999), donde la defensa común entra de manera clara y detallada y con el que, por primera vez en la historia de la Unión Europea, se cuenta con una normativa clara en relación con la defensa. Este proceso llevaría a la cumbre de St-Malo (Francia y Reino Unido, Diciembre 1998), en el que se preconizaba una capacidad independiente política y militar para la Unión Europea; al Consejo Europeo de Colonia (Junio 1999) con la Declaración del reforzamiento de la Política Europea Común de Seguridad y Defensa (CESDP) y, por fin, al Consejo de Helsinki (Diciembre 1999) en el que, en el contexto de la CESDP, se establecía el objetivo de «Headline Goal».

Es decir, se había hecho realidad un amplio consenso en el seno de la Unión Europea, y especialmente entre los principales países fabricantes de armamento, en el que se concluía que una política de defensa europea necesitaba de una amplia base tecnológica e industrial para lograr una aceptable autonomía y un mayor equilibrio trasatlántico.

En este contexto se produjo la Declaración Trilateral, el 9 de Diciembre de 1997 (dos meses después de la firma del Tratado de Amsterdam), en la que los Jefes de Estado y Gobierno de Alemania, Francia y Reino Unido, instaban a los líderes nacionales de la Industria de Defensa a pre- 
sentar, a fecha del 31 de Marzo de 1998, un plan detallado de reestructuración e integración industrial. Esta Declaración dirigida al sector aeroespacial y de electrónica de defensa, se limitó en un principio a la formación de un grupo aeroespacial europeo cuyo núcleo inicial básico sería la transformación del Grupo de Interés Económico (GIE) Airbus, formado por Aerospatiale, BAe, DASA y CASA, en una verdadera empresa. El conocimiento de la fusión entre Boeing y McDonnell Douglas convenció a los gobiernos y a la industria de la necesidad estratégica de incluir actividades militares en la futura empresa.

El 27 de Marzo de 1998, las cuatro empresas del Consorcio Airbus presentaron un documento a sus Gobiernos sobre la reestructuración propuesta en el que, además de los principios fundacionales, se planteaban una serie de cuestiones que deberían aclararse previamente a cualquier propuesta industrial. Este informe fue además enviado a Saab de Suecia y a Finmeccanica de Italia.

En rápida continuación del proceso, el 9 de Julio de 1998, los Ministros de Industria de los seis países (ya incluidos Suecia e Italia, aunque ajenos al programa Airbus) formularon una Declaración en la que se fijaban unos criterios para la reestructuración e instaban a las seis industrias a resolver lo antes posible los asuntos pendientes y presentar un nuevo documento a finales de Octubre con los términos para crear una «Airbus Single Corporate Entity» en 1999 como primer paso y núcleo para la creación de la futura «European Aerospace Denfence Company (EADC)». El informe en respuesta a dicha Declaración, elaborado conjuntamente por las seis industrias, fue finalmente presentado a mediados de Noviembre de 1998.

Evidentemente, dada la complejidad de una integración a seis, no se llegó nunca a una fase de verdadera negociación y todo quedó en un intercambio de criterios y posibles líneas de acción. Se logró el acuerdo en algunos conceptos básicos: una sola Compañía integrada (EADC); gestión como una sola entidad; líneas de negocio definidas por criterios financieros y económicos constituyendo el principal objetivo el «shareholder value"; el ámbito de actuación de EADC incluiría como núcleo básico de negocio actividades aeroespaciales civiles y militares y sistemas aeroespaciales y de defensa.

Sin embargo, las cuestiones sobre la estructura accionarial de EADC y la protección de los derechos de los accionistas, así como el intento de inclusión de todos los programas de aviones de combate (integración de Dassault Aviation) dentro de la única empresa, probaron la imposibilidad de llegar a mínimos acuerdos dada, además, la diferencia de tamaño de las diferentes compañías. 
No obstante, los pasos estaban dados, la necesidad demandaba decisiones rápidas y las Compañías comenzaron a mirarse y a considerar quién se uniría a quién para encontrar salidas más simples que llevaran a soluciones viables.

\subsubsection{El escenario posterior.}

A la vista del fracaso de la creación ex novo de una única Industria Europea Aeroespacial de Defensa -EADC-, por imposibilidad de conjugar los intereses de las seis industrias líderes, a los que se sumaban los intereses de los correspondientes gobiernos, pero ya puesto en marcha un proceso imparable en una carrera contra el tiempo, conviene analizar la situación de los principales actores en ese entorno temporal, centrando el análisis en los cuatro miembros del Consorcio Airbus, a quienes, en principio, iba dirigido el requerimiento de los Jefes de Gobierno y que constituían el grupo más importante de la industria aeroespacial en Europa.

Aerospatiale, líder real del Consorcio Airbus, era una compañía de propiedad estatal cuya privatización constituía un requisito previo para futuras fusiones, cumpliendo las condiciones ya imperantes en el mercado. El Gobierno francés tomó la decisión en Julio de 1998 de proceder a su privatización fusionándola con Matra Haute Technologies, del grupo Lagardere. La privatización, requería una serie de complejas operaciones encaminadas a solucionar los problemas de relación tanto con ThomsonCSF como con Dassault. No obstante, todos estos problemas habían llegado a una solución negociada y las condiciones financieras de la fusión estaban terminadas en Febrero de 1999, de tal forma que su salida a la Bolsa de París tuvo lugar el 4 de Junio de 1999. Su estructura accionarial final, quedó de la siguiente manera: Lagardière como accionista de referencia el 33\%; el Estado francés el 47,7\% y, el resto, flotante (público, instituciones y empleados) el 19,3\%. Constituyó todo un récord de conjunción de voluntades para lograr un importantísimo objetivo de consolidación de la industria nacional, pero que todavía se quedaba un paso corto del objetivo final de integración en una verdadera industria aeroespacial europea.

CASA, el socio más pequeño del Consorcio Airbus, era y es, la compañía europea independiente más antigua en el sector aeroespacial, creada en 1923 y con la tradición de haber sido siempre el mayor suministrador del mercado español. En los últimos ocho años y con una acertada estrategia a largo plazo, consiguió su dimensión óptima con una excelente rentabilidad, producto de una imaginativa política de inversiones que 
ha resultado en la creación de centros industriales de excelencia, especialmente en las áreas de fibra de carbono y aviones de transporte militar. Con una participación de un 13,65\% en el programa Eurofighter y un $4,2 \%$ en Airbus, reunía unas excelentes condiciones para dar un paso hacia la integración con cualquiera de los líderes europeos.

Empresa de propiedad estatal prácticamente en su 100\% (la Sociedad Estatal de Participaciones Industriales -SEPI- como único accionista), se encontraba prácticamente en la misma situación que Aerospatiale. Sin embargo también en 1998 la SEPI anuncia la privatización de CASA con el objetivo de integrarla con un socio europeo. La propia AerospatialeMatra, BAe (todavía BAe) y Finmeccanica eran los previstos candidatos, pero fue sin embargo la alemana DASA, en parte como producto de su frustración en las negociaciones con BAe, la que al final daría el salto transnacional en su unión con CASA.

La situación y evolución de DASA y BAe debe tratarse conjuntamente, ya que comenzó como un proyecto natural y de fácil solución y terminó, sin embargo, de forma totalmente inesperada con un tremendo viraje. La aproximación de ambas tuvo lugar desde comienzos de 1998, incluso al mismo tiempo, en que tenían lugar las complicadas negociaciones a seis para la creación de EADC. Precisamente por esta circunstancia, hubiese parecido lógico que en estas negociaciones estuviese incluida Aerospatiale, pero el recelo de ambas compañías totalmente privadas y con la misma filosofía de mercado hacia la francesa, en la que aún el estado tenía una fuerte participación $(47,7 \%)$, puso una insalvable barrera en las negociaciones para la integración a tres. Por tanto, el proceso anglo-alemán, BAeDASA, estaba prácticamente finalizado a finales de 1998 para la creación de un grupo transnacional totalmente privatizado y que pretendía ser el núcleo inicial aglutinante para futuras integraciones.

Y aquí se produjo el viraje; GEC anunció su decisión de desprenderse de su división de electrónica de defensa, Marconi, lo que para BAe representaba una tentadora y quizá única oportunidad de crecer en una dirección en la que carecía de tecnología; podía convertirla de la noche a la mañana, de diseñador fabricante de plataformas, en diseñador y fabricante de verdaderos sistemas completos, incrementando enormemente sus posibilidades de mercado. Este totalmente inesperado cambio de orientación dejó sorprendido, no sólo al gobierno alemán, sino incluso al propio gobierno del Reino Unido que hubiese preferido una fusión transnacional en apoyo del proyecto de reforzamiento de una política europea de defensa común proclamada en la cumbre de St-Malo en Diciembre de 1998. Pero ni siquiera al alto precio pagado por BAe fue obstáculo para consolidar esta fusión. 
El escenario de este último acto, preludio de la integración posterior, quedaba configurado de la siguiente forma a principios de 1999:

Aerospatiale Matra se situaba como segunda empresa europea y como quinta en el orden mundial en los sectores aeroespacial y de defensa, con un volumen de ingresos en 1998, de 11,6 billones de euros (bn $€$ ), habiéndose convertido en una empresa privada, no obstante la aún fuerte participación del gobierno.

BAe, convertida ahora en Nueva BAe (posteriormente en BAe Systems: BAeS), había pasado a ser la tercera empresa en la clasificación mundial y la primera europea en los campos aerospacial y de defensa con un volumen de ingresos en 1998, de 17,4 bn $€$ Su brusco abandono de las avanzadas negociaciones con la alemana DASA, había deteriorado de tal modo las relaciones que hacía imposible cualquier intento futuro de integración entre ambas.

DASA, profundamente agraviada, se había quedado sola en su empeño europeo y comenzó a considerar una alianza al otro lado del Atlántico; no hay que olvidar el lazo existente como subsidiaria del grupo Daimler-Chrysler. Por otra parte, sus relaciones con el socio francés de Airbus, Aerospatiale, después de su fusión con Matra y con su actual condición legal de compañía privada, comenzaron a mejorar ostensiblemente. Su posición quedaba invariable como tercera empresa europea y sexta en el mundo con un volumen de ingresos en 1998, de 9,8 bn $€$

CASA, no obstante su dimensión comparada con los otros tres socios de Airbus, era un plato muy apetecible al que se dirigían las miradas de todos. Su condición de líder nacional en el sector aerospacial, el anuncio formal de su inmediata privatización y su envidiable situación financiera, industrial, comercial y tecnológica en áreas muy interesantes de cara al futuro la habían situado en el punto de mira. Ocupaba el sexto puesto de la industria aeroespacial europea y el décimo de la mundial, con un volumen de ingresos de 1 bn $€$ en 1998.

Esta era la situación en la parrilla de salida para la carrera final hacia la integración transnacional. No hay que olvidar que los términos de referencia eran los dos gigantes americanos: Boeing con un volumen de ingresos de 50,1 bn $€$ en 1998 y, Lockheed Martin con 23,1 bn $€$. Ver anexo n. ${ }^{\circ} 3$.

\subsubsection{El nacimiento de EADS}

Dada la situación descrita en el panorama europeo, no es por tanto de extrañar que en Junio de 1999, durante el Salón Aeronáutico internacional de Le Bourget, en París, DASA y la SEPI, como único accionista de 
La industria aeroespacial: un modelo...

CASA, firmaran, tras una corta negociación, una Carta de Intenciones (LO1) que suponía la privatización final de CASA. Se crearía para ello una compañía de holding, en la que DASA poseería un $87 \%$ y la SEPI el resto, con el compromiso de esta última de poner sus acciones en la Bolsa en los siguientes tres años.

Por primera vez en Europa, dos líderes nacionales de la industria aeroespacial habían dado el paso decisivo hacia la verdadera integración. Quizá pudiera parecer extraño que dada la diferencia de dimensión y situación de ambas compañías tanto en el concierto europeo como en el mundial, hubiera sido éste un paso acertado para situar a la industria europea frente a la enorme competencia americana. Pero no debe olvidarse que fue sólo un primer paso y que, considerando ambos mercados, el europeo y el mundial, fue un primer paso muy acertado. La participación de ambos socios en los programas Airbus y Eurofighter sumaba el $42,1 \%$ y $43 \%$ respectivamente, con lo cual se situaban en una posición de privilegio respecto a los otros dos socios. Al mismo tiempo, CASA aportaba al grupo su amplia experiencia comercial en el mercado internacional, en especial el iberoamericano, experiencia de la que DASA carecía. Y desde el punto de vista político, se ponía la primera piedra del proceso que comenzó en St-Malo en Diciembre de 1998, para la implementación de una política de defensa común europea dentro del marco de la Política Común Europea de Seguridad y Defensa (CESDP).

Pero durante los cuatro meses que siguieron a la firma de la Carta de Intenciones y en paralelo con las negociaciones DASA-CASA para su fusión, tuvo lugar una maniobra de mayor calado encaminada hacia la fusión de Matra-Aerospatiale y DASA. No se contó para ello con el gobierno español -con la SEPI- y la negociación se llevó a cabo con todo secreto entre Jürgen Schremp (Daimler-Chrysler) y Jean -Luc Lagardère (dejando casi al margen a la anterior Aerospatiale). Los anteriores deseos del gobierno francés de Lionel Jospin de llegar a una solución verdaderamente europea, encontraron un camino más llano al aprovechar la gran frustración de DASA ante el desaire de BAe.

$\mathrm{Al}$ éxito de la operación contribuyó el dejar las manos libres a hombres de negocios totalmente del sector privado unido a unas excelentes relaciones entre los mismos. El resultado no se hizo esperar y a sólo cuatro meses desde el comienzo de las negociaciones, el 14 de octubre de 1999, Lagardère, el Gobierno francés y Daimler-Chrysler anunciaron el acuerdo para la fusión de sus respectivas actividades aeronáutica, espaciales y de defensa.

Había nacido el nuevo grupo EADS, la Sociedad Europea Aeronáutica, Espacial y de Defensa, quizá como una consecuencia de la frustra- 
ción de DASA dejada en la estacada por BAe, que fue capaz de digerir esa amarga píldora y llegar al acuerdo preparado y deseado por Francia.

CASA, que pareció quedar abandonada, estaba implícitamente comprendida en ese trato. No cabe duda que DASA tenía que hacer honor a su compromiso tras la firma de la LOI en Junio de 1999, por lo que conjuntamente con Aerospatiale Matra se iniciaron las negociaciones con CASA para su inclusión, que finalizaron a finales del mes de Noviembre y, así, el 2 de Diciembre de 1999, se produjo la firma para la integración de CASA en EADS.

Se configuraba de este modo EADS como la primera agrupación integrada de negocios transnacional Europea en el sector aeroespacial. La nueva compañía se convertía en uno de los actores principales en el mercado mundial, compitiendo en todas las áreas clave de negocio aeroespacial tanto civil como militar: aviación civil y militar, helicópteros, satélites y lanzadores, misiles, electrónica de defensa y comunicaciones.

EADS representaba la primera -y tan deseada- materialización industrial de los objetivos de la Comisión Europea de integración de la industria Europea Aeroespacial y de Defensa. Mientras que especialmente en la última década se habían dado pasos muy importantes por los Gobiernos hacia una mayor integración en las Políticas Europeas de Defensa (Maastrich, el Tratado de Amsterdam sobre una política común de armamento en uno de sus apartados, initiativas del GAEO para la creación de una Agencia Europea de Armamentos), la estructura del tejido industrial europeo se ha desarrollado básicamente siguiendo líneas de intereses nacionales, con las excepciones y avances que se han analizado. EADS representa la culminación de todos los esfuerzos y el primer ejemplo pan-europeo de consolidación industrial, tal como se preconizaba en el Comunicado de la Comisión al Parlamento Europeo en Noviembre de 1997.

EADS se sitúa como la tercera Compañía mundial de la industria aeroespacial, detrás de Boeing e inmediatamente detrás (casi en paridad) con Lockheed Martin. Su situación comparativa en el orden mundial puede verse en el Anexo n. ${ }^{\circ} 3$.

Con unos ingresos combinados de aproximadamente 21 billones de Euros (en 1998) y una plantilla de 96.000 personas, se coloca en posiciones de liderazgo en todos los segmentos de los sectores aeroespacial (civil u militar), de electrónica de defensa y comunicaciones (ver Anexo n. $\left.{ }^{\circ} 4\right)$. 


\subsubsection{Estructura Accionarial de EADS}

Accionariado de EADS

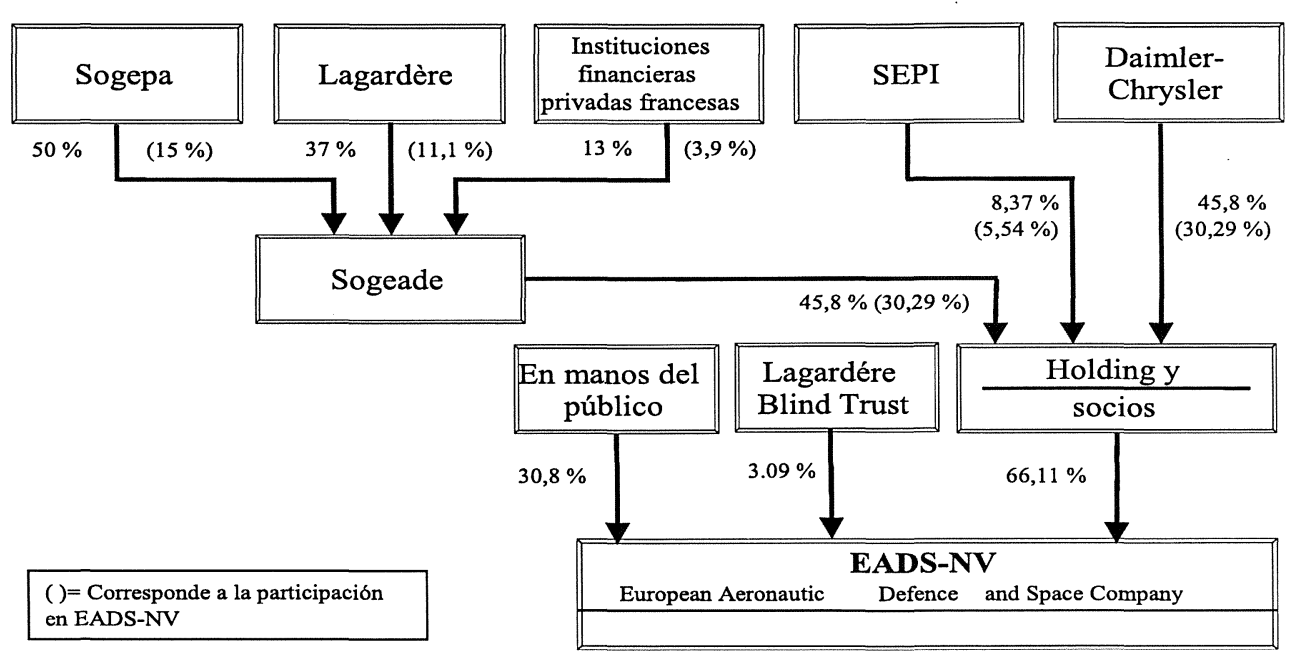

En un primer nivel, Daimler Chrysler está en posesión del 30,29\% de las acciones en EADS, a través de un holding (Daimler Chrysler Luft und Raumfahrt Holding). El grupo francés tiene también un 30,29\% de las acciones de EADS a través de una compañía de gestión (SOGEADE), controlada a su vez en un $50 \%$ por el Estado francés (vía una compañía de holding, SOGEPA), $37 \%$ por Lagardère y $13 \%$ por Instituciones privadas Francesas. SEPI mantiene el 5,54\% de las acciones de EADS.

Como resultado, la propiedad definitiva de EADS se divide entre Daimler-Chrysler (30,29\%), Lagardère (14,19\%), el Estado francés (15\%), Instituciones Francesas privadas (3,9\%), SEPI $(5,54 \%)$ y accionistas privados -Público- $(30,8 \%)$. Las acciones de EADS están registradas en las Bolsas de Frankfurt, París y Madrid.

EADS estará controlada conjuntamente por Daimler-Chrysler, Lagardère y el Estado Francés, a través de un Holding holandés (Sociedad limitada registrada en Holanda por motivos fiscales) que actúa en representación de Daimler-Chrysler Sogeade y SEPI; esta última ha transferido todas sus acciones al Holding, pero manteniendo los derechos económicos de las mismas. A cambio de ello, Daimler-Chrysler y Sogeade mantendrán cada uno el $45,8 \%$ de las acciones en el Holding y la SEPI, el $8,37 \%$.

Al igual que el Holding, y también por razones fiscales, EADS está registrada como una Compañía Holandesa. 
Con esta estructura accionarial se ha tratado de establecer el equilibrio entre los principales accionistas y de establecer un proceso de la decisión conjunto para los asuntos clave. Pero como fácilmente se desprende de la propia estructura, el peso franco-alemán es incuestionable. Ninguno de ellos puede hacerse con el control de EADS por el principio de igualdad de derechos que, según los acuerdos es inviolable. Si alguno de los accionistas desea vender, sólo puede hacerlo en la Bolsa y ello, no altera los derechos en EADS, desde el momento en que acciones y derecho a voto está perfectamente separados.

Para poder poner en marcha EADS todos los actores tuvieron que hacer ciertas concesiones. Los alemanes cuyo principal obstáculo para la fusión con Matra-Aerospatiale era la presencia del Estado francés, tuvieron que resignarse a que fuese todavía un fuerte accionista en EADS que mantiene unos derechos importantes de control, prácticamente los mismos que mantenía en Aerospatiale-Matra. Los franceses por su parte han tenido que aceptar la paridad con la parte alemana a la que, industrialmente, la consideran muy por detrás desde el punto de vista tecnológico. La SEPI, por su parte, tiene solamente una pequeña participación, aunque con algunos derechos, por un tiempo limitado ya que ha manifestado su deseo de vender en Bolsa antes del 2003, pero que pudiera no hacerlo y así mantener esos derechos.

La estructura accionarial, en consonancia con las previsiones establecidas en el Acuerdo entre los accionistas, permanecerá invariable durante los tres primeros años desde la formalización de la Compañía (hasta el 2003); solamente la SEPI puede ejercer su derecho de vender el total de su participación si así lo desea. Pasado este período de salvaguarda, establecido para proporcionar estabilidad durante los necesarios ajustes, cualquiera de los socios puede vender su participación en EADS. Ciertamente, si alguno de los «poderosos» se retira, la estructura de gestión corporativa sufrirá un drástico cambio.

\subsubsection{Estructura de Gestión de EADS}

Está constituida en dos niveles: un Comité de Dirección y un Comité Ejecutivo.

En el Comité de Dirección Manfred Bischoff (Alemania) y Jean-Luc Lagardère (Francia) actúan como Co Presidentes no ejecutivos. Conforman además el Comité nueve directores: dos alemanes designados por Daimler-Chrysler, dos franceses designados conjuntamente por Lagardère y el Estado francés, un español designado por la SEPI, los dos Co CEOS del Comité Ejecutivo de EADS y dos directores externos. Para sos- 
layar un posible papel estratégico del director español, entre alemanes y franceses, han quedado establecidas unas reglas de votación, según las cuales, se debe obtener siempre una mayoría cualificada de por lo menos siete votos favorables, de un total de once.

\section{Organigrama de EADS}
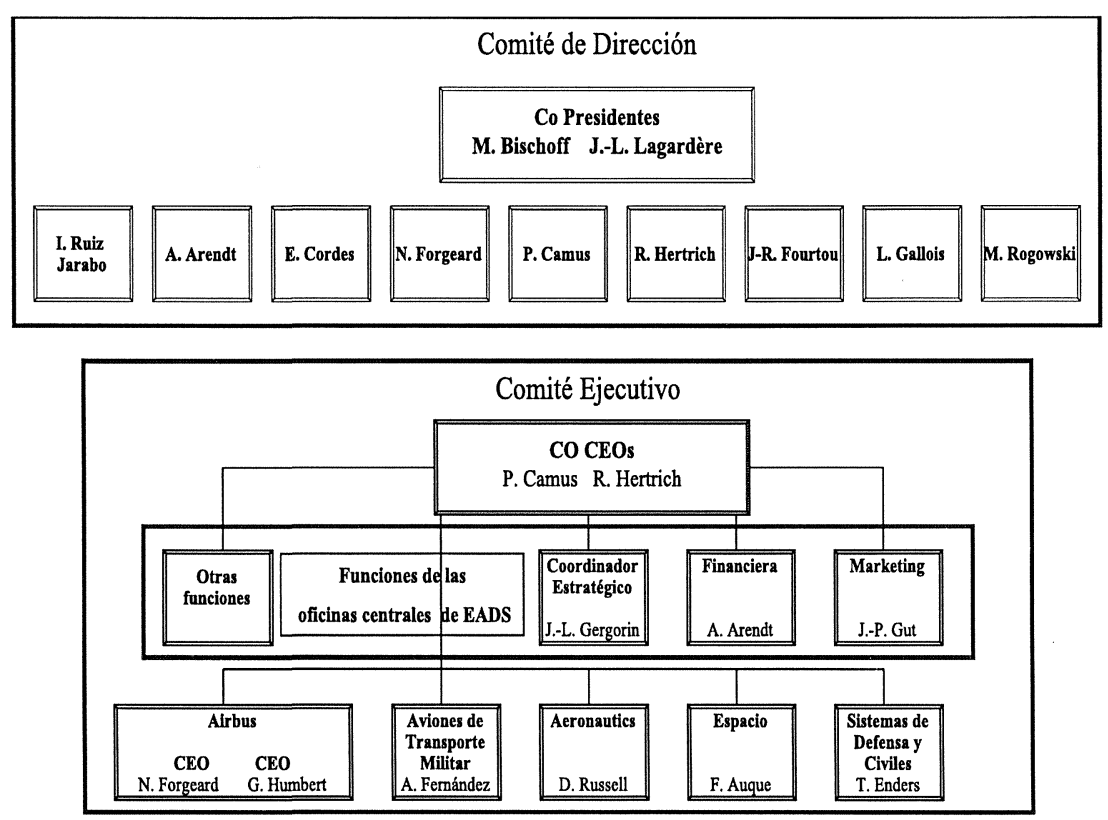

En el Comité Ejecutivo co-presiden los dos CEOS, Rainer Hertrich (Alemania) y Philippe Camus (Francia); el resto del Comité está formado por los directores de las Divisiones y de las diversas Funciones de la Administración Central de EADS (Estrategia, Marketing y Finanzas).

Las áreas de actividad, se estructuran en cinco Divisiones: Airbus (con dos directores francés y alemán), Actividades Aeronáuticas (Alemán), Espacio (Francés), Aviones de Transporte Militar (Español) y Sistemas Civiles y de Defensa (Alemán). Cada una de estas organizaciones o Divisiones es totalmente responsable de su ejecución y resultados y debajo de ellas están integradas las denominadas Unidades de Negocio.

La estructura de gestión de EADS se caracteriza a todos los niveles por el peso decisivo y aparentemente paritario de Daimler Chrysler y Lagardère, porque no debe olvidarse que, a través de este último, el Estado francés puede ejercer su influencia por medio de SOGEADE. En última instancia, todas las decisiones importantes de carácter estratégico o comercial relativas a la integridad de EADS requieren del consentimiento 
y del acuerdo entre dichos actores. La SEPI, en este concierto, tiene únicamente un derecho de veto en relación con el Plan Industrial de la antigua CASA:

\subsection{La situación actual de la Industria Aeroespacial Europea}

Con dos años de retraso con respecto a los Estados Unidos pero todavía a tiempo, se ha llegado a la situación actual, en la que la industria europea aeroespacial y de defensa puede medirse en un plano de igualdad con la industria americana. El peligro, si no de desaparición, sí de quedar reducida a un mero papel subsidiario al no poder competir con el gigante americano, ha movilizado voluntades políticas en los Gobiernos europeos -en especial en los principales países productores de armamento- y acelerado los procesos de negociación de las empresas para adaptarse a las nuevas exigencias del mercado. No cabe duda que se ha dado un paso de gigante en solo esos dos años, limando asperezas, salvando ideologías encontradas -(Europeísmo contra Atlantismo)-, suavizando nacionalismos demasiado anclados en el principio de soberanía y sobre todo, utilizando nuevos conceptos de racionalización del mercado. En esta carrera, la industria ha sido el motor y ha ido siempre por delante, sorprendiendo incluso a los propios Gobiernos.

Con la aparición de Boeing -tras la absorción de Mc Donnell Douglasen Agosto de 1997, parece que cundió una consigna tácita: «Salvar la industria europea», que desencadenó el proceso y produjo el milagro.

EADS y BAe Systems son los dos líderes europeos indiscutibles de la industria aeroespacial con una característica bien diferenciada: EADS tiene su principal peso en el campo civil (principalmente AIRBUS) y, BAeS en el campo de defensa. En cierto modo son muy homogéneos con Boeing y con Lockheed Martin respectivamente.

Por otra parte, y muy importante, ambas empresas europeas están ligadas estructural y legalmente, por haber formado diversas Empresas Conjuntas (Joint Ventures), siendo las mas importantes:

En la nueva compañía AIRBUS (AIC), BAeS, tiene el $20 \%$ de su capital, con representación en el consejo de accionistas, y en el comité ejecutivo, con veto en las decisiones estratégicas.

En aviones de combate, por ser miembros del Consorcio Eurofighter, EADS participa con un $43 \%$ y BAeS con el 37,5\%. En caso de formación de la sociedad conjunta EMAC, entre EADS y Finmeccanica (Italia), EADS pasaría a controlar el 62,5\% del programa.

En misiles, la actual integración de MBD (al 50\% entre Matra y BAe Systems) con AMS (Alenia Marconi Systems) controla aproximadamente 
La industria aeroespacial: un modelo...

el $80 \%$ del mercado europeo, con los programas en curso, Meteor, Storm Shadow y ASRAM.

Evidentemente, dadas estas sinergias y su perfecta complementariedad en los campos civil y militar, si en algún momento se llegara a producir la fusión de ambas, se habría creado el verdadero gigante europeo.

Algo mas lejos pero con un peso específico apreciable en la industria europea es necesario citar:

Thomson-CSF es el indiscutible líder europeo en electrónica de defensa, muy por encima de BAeS y con una gran penetración en el mercado internacional. Su reciente alianza con Alcatel le proporciona oportunidades estratégicas en los campos militar y civil.

Dassault Aviation es quizá la mayor incógnita; aunque continúa siendo independiente, tiene un importante accionista -simplemente accionista- en EADS la cual posee casi un $46 \%$ de su capital. Su integración en EADS es un paso obligado, únicamente habrá que esperar el momento oportuno pero, en cualquier caso, antes de que surja el próximo programa europeo del avión de combate que suceda al Eurofighter.

Finmeccanica, la compañía de holding italiana líder nacional que controla la mayor parte de su industria de defensa. El holding constituye un grupo privado aunque el Estado italiano conserva aún el 30\% de su capital. Sus actividades se abren a todos los campos de la industria aeroespacial y de defensa: aviones militares y civiles, satélites, helicópteros, misiles y electrónica de defensa. Su estrategia se ha dirigido hacia la participación en sociedades conjuntas (Joint Ventures), en todos estos sectores. Su proyecto actual (como ya se ha mencionado) es la formación de EMAC al 50\% con EADS, en la que se integrarían las actividades de ambas en aviones de combate, aviones regionales de transporte, aviones de entrenamiento y aeroestructuras.

\subsection{El papel de los Gobiernos}

Hasta ahora se ha estudiado el proceso de consolidación e integración de la industria aeroespacial, en especial de la europea, prácticamente solo desde el lado de la oferta. Queda por considerar, aunque sea en una breve reseña, el lado de la demanda; es decir, el esfuerzo regulador de los gobiernos para homogeneizar la estructura del mercado y el propio funcionamiento de la demanda por un lado y, por otro, los intentos de llegar a un espacio común en el ámbito de la política de seguridad y defensa, que va desde la puesta en marcha de la ESDI (Identidad Europea de Seguridad y Defensa), hasta el establecimiento de la CESDP (Política Europea Común de Seguridad y Defensa). 
3.5.1. Iniciativa de los Gobiernos europeos para la reestructuración de la Industria de Defensa

La labor reguladora y armonizadora de los Gobiernos europeos en política de armamento podemos situarla en un origen, probablemente artificial, y a partir de ahí hacer un breve repaso histórico para llegar a la actualidad. Ha ido siguiendo en cierto modo y paralelamente las mismas fases que la Industria en este proceso de cooperación, consolidación e integración.

En 1976 se constituyó el Grupo Europeo Independiente de Programas (IEPG), formado por miembros europeos de la OTAN y con el objetivo de mejorar la cooperación en Europa en materia de Defensa.

En el Tratado de Maastrich en 1991 se fija, como uno de sus objetivos, el establecimiento de la Agencia Europea de Armamentos para la totalidad de la Industria Europea de Defensa.

En 1992 los Ministros de Defensa del IEPG decidieron en Bonn integrar las actividades de este Grupo en la UEO, creándose el Grupo de Armamentos de la Europa Occidental GAEO (WEAG en nomenclatura inglesa). Su objetivo era el mismo que el del IEPG.

Posteriormente, los Ministros de Defensa pertenecientes al GAEO decidieron establecer la Organización de Armamentos de la Europa Occidental, OAEO (WEAD en nomenclatura inglesa), con el objeto de regular procedimientos, organización, contratos, exportación, etc. en todos los proyectos de cooperación de armamento. La Carta de la OEAO fue aprobada en 1996 y la Organización comenzó sus funciones en 1997, convirtiéndose en un cuerpo subsidiario de la UEO, por un acuerdo posterior de quien toma su personalidad jurídica. Era el primer paso para el establecimiento de una Agencia Europea de Armamentos, pero las condiciones del acuerdo solo permitieron llevar a cabo actividades de investigación y desarrollo (programas EUCLID y THALES).

Los Ministros de Defensa de los 13 países del GAEO deciden en Erfurt en la Convención de otoño de 1997, la puesta en marcha de un plan en el que se incluye el establecimiento de una Agencia Europea de Armamentos y para ello se encarga la redacción de un Plan Director (Master Plan) a los Directores Nacionales de Armamento. Para su consecución se incluía un calendario de hitos que concluiría en el otoño de 2001 con la aprobación de los Ministros, siempre que se dieran las condiciones políticas que lo hicieran viable. Es decir, la Agencia Europea de Armamentos debería entrar en funciones en dicha fecha.

En un paso que podríamos denominar intermedio, pero respondiendo precisamente a esta necesidad de gestión conjunta, se crea la OCCAR, 
La industria aeroespacial: un modelo...

Organización Conjunta para Cooperación en materia de Armamentos, en 1995 por Francia y Alemania, uniéndose en 1996 el Reino Unido e Italia. Se considera la OCCAR como la fase preliminar de una posterior Agencia Europea de Armamentos y su objetivo es el de servir de instrumento de gestión de los grandes programas conjuntos de armamento. Su Convención fue aprobada y firmada en Septiembre de 1998 (en Farnborough) por los Ministros de Defensa de los países participantes y en ella se establecen unos principios comunes que de forma clara favorecen la cooperación industrial, la armonización de requisitos y las inversiones y transferencias tecnológicas. España está en proceso de ratificación de la Convención.

Los Ministros de Defensa de Francia, Reino Unido y Alemania se reúnen en Londres en Enero de 1998, donde se presenta un Memorándum de Entendimiento (MOU) por el Reino Unido, en el que se asume el papel regulador de los Gobiernos en la tarea de reestructuración de la Industria de Defensa Europea y se propone un tratamiento común de las áreas que se consideran clave: Seguridad del Suministro, Exportaciones de Defensa, Seguridad de la Información, Tecnología y Desarrollo y Tratamiento de los Derechos de Propiedad Intelectual.

En la declaración conjunta de los Ministros de Defensa de Alemania, Francia, Reino Unido, España e Italia, en Marzo de 1998, en París, se vuelve a afirmar que los protagonistas de la reestructuración industrial han de ser las empresas y se adquiere el compromiso de los Gobiernos de acometer el proceso regulador nacional para facilitar la integración transnacional. Los Ministros acordaron que, para capitalizar la reestructuración industrial a nivel europeo, sería prioritario para ellos la eliminación de los obstáculos en las áreas de Seguridad en el Suministro, Procedimientos de Exportación, Financiación de Investigación y Desarrollo, Seguridad de la Información y Habilitación del Personal y Derechos de Propiedad Intelectual.

Los Ministros decidieron que firmarían en Junio de 1998 una Carta de Intenciones (LOI) que explique los objetivos y principios para gestionar dichos temas y exponga la organización y calendario de. las tareas a realizar. Se invita a Suecia a participar en dicho esfuerzo.

El 6 de Julio de 1998 se firma por los seis países (ya incluida Suecia) la Carta de Intenciones (LOI) sobre las medidas para «Facilitar la Reestructuración de las Industrias de Defensa»,

Como consecuencia de la LOI, se instituye un Comité Ejecutivo para gestionar el proceso y se crean seis Grupos de Trabajo, uno por cada área prioritaria, para estudiar y llegar a conclusiones sobre protocolos, acuerdos y pactos que puedan ser firmados antes de finales de 1999. 
El 27 de Julio de 2000 se firmó en Farnborough el Acuerdo Marco entre los seis países, relativo a las medidas encaminadas a facilitar la reestructuración y funcionamiento de la Industria de Defensa (Acuerdo Marco sobre la LOI). El acuerdo entró en vigor el 18 de Abril de 2001.

España ratificó el Acuerdo Marco el 21 de Junio de 2001 y su entrada en vigor se produjo el 11 de Agosto de 2001.

Italia es el único país que aún está en proceso de ratificación del Acuerdo. No obstante, todo lo en él contenido está en pleno vigor entre los países que lo han ratificado.

Queda un paso determinante que dar: la decisión de los Ministros de Defensa de aprobación e implantación del Master Plan para la Agencia Europea de Armamentos, si existen las necesarias condiciones políticas. La aprobación estaba programada para el otoño del 2001.

Quedan todavía muchos cabos sueltos y la tarea es complicada; no hay un enfoque común para la resolución de los problemas y la coordinación de los diversos organismos es lenta y escasa. Pero la voluntad de los Gobiernos es clara y el papel de los Ministros de Defensa y de los Directores Nacionales de Armamento de los países implicados será determinante en los próximos años. Mientras tanto, ya hay en funcionamiento, aunque aún no a pleno rendimiento, dos instrumentos básicos: la LOI como estructura fundamental y la OCCAR como transición hacia la Agencia Europea de Armamentos y que, de momento, es capaz de gestionar los grandes programas de armamento tales como: el Milán, Roland, Tigre MRAW/GTX (por citar algunos) y en un futuro muy próximo, el del avión de transporte militar A400M.

Se ha andado ya mucho camino y lo conseguido, especialmente en los últimos años, abre ciertamente un horizonte muy esperanzador.

\subsubsection{Hacía una Política Europea Común de Seguridad y Defensa}

Como ya se ha visto anteriormente (apartado 3.3.1), la búsqueda y consecución de un espacio común europeo de Seguridad y Defensa, tenía y tiene como requisitos previos, la reestructuración de la industria de defensa en entidades transnacionales por un lado y, por otro, la normativa reguladora de los Gobiernos, para dotar de racionalidad y eficacia el funcionamiento del libre mercado, ajustando la oferta a la demanda.

En la búsqueda de ese espacio común, podemos situar como origen el hito significativo conseguido con el Tratado de Maastrich, en Diciembre de 1991, con la adopción por la Unión Europea - y desarrollo posterior - de un proyecto para una política exterior y de seguridad común (PESC). En el Tratado se prevé la formación de una verdadera identi- 
dad europea de defensa y designa a la Unión Europea Occidental (UEO), como parte integrante de la Unión Europea, para elaborar y llevar a cabo las acciones de la UE que tuvieran implicaciones en el terreno de la defensa.

Una iniciativa paralela, surgida en el Seno del Consejo del Atlántico Norte, tuvo lugar en su reunión de Bruselas en Enero de 1994, en la que de forma no oficial se puso en marcha la Identidad Europea de Seguridad y Defensa (ESDI), concebida de modo general como un instrumento que permita a los países europeos asumir la responsabilidad de una mayor participación en misiones de seguridad por medio del acceso a aquellos elementos y capacidades de la Alianza de los que los miembros europeos no disponen. Dos años más tarde, en la reunión ministerial de la OTAN en Berlín, en Junio de 1996, se dio el espaldarazo a la ESDI y al instrumento militar que la sustentaba, los Grupos de Combate Combinados Conjuntos (CJTF: Combined Joint Task Forces).

Independientemente de sus altibajos, la ESDI como iniciativa de la OTAN, fue sin embargo el vector que impulsaría a la Unión Europea hacia el espacio común de Seguridad y Defensa.

Y así, en el Tratado de Amsterdam (acordado en el plano político en Junio de 1997, firmado en Octubre de ese año y vigente desde el 1 de Mayo de 1999), es donde por primera vez la defensa común entra de manera específica, detallada y con una normativa clara. Lo que lleva el proceso a la cumbre de St-Malo (4 Diciembre 1998), en la que los Jefes de Estado y de Gobierno de Francia y del Reino Unido preconizaban una capacidad independiente, política y militar para la Unión Europea; una total y rápida implantación de las provisiones del Tratado de Amsterdam: responsabilidad del Consejo Europeo para decidir en la progresiva construcción de una política común de defensa en el marco de la Política Común Exterior y de Seguridad (CFSP).

Al hilo de los acontecimientos, en Marzo de 1999, se produjo el lanzamiento de la «Allied Force» para la ofensiva de Kosovo, quedando meridianamente patente que en Europa no podía conjuntarse una fuerza de combate similar a la proporcionada por Estados Unidos, para hacer frente a una crisis en el propio continente. Por ello, como lección aprendida y solución a medio plazo, en Abril de 1999, se definieron en OTAN las líneas maestras de la Iniciativa de Capacidad para Defensa (DCI: Defence Capability Initiative) para el desarrollo de la futura estructura de defensa Europea y equilibrar esa tremenda diferencia. El objetivo a conseguir es el de mejorar la interoperabilidad de las fuerzas de la OTAN y asegurar la eficacia de las operaciones en todo el aspecto de misiones de la Alianza. 
Posteriormente, el 4 de Julio de 1999, en el Consejo Europeo de Colonia, se produce la Declaración del Consejo sobre el reforzamiento de la Política Común Europea de Seguridad y Defensa (CESDP). La Unión Europea se arroga la facultad de disponer de la estructura institucional necesaria para tomar decisiones en dichas materias.

Y por fin, en el Consejo Europeo de Helsinki, el 11 de Diciembre de 1999, se aborda con un alto nivel de detalle y de compromiso el gran tema de la defensa europea que pone de manifiesto una decidida voluntad política y de plena madurez en la toma de decisiones sobre la defensa común. $\mathrm{Y}$ es, precisamente en esta Cumbre, donde quedan definidas las líneas maestras de los objetivos de fuerzas militares a alcanzar («Headlines Goals»). Como primera providencia se decide la creación de una Fuerza de Reacción Rápida Europea con unos efectivos de 50.000 a 60.000 hombres, con una disponibilidad operativa dentro de los 60 días y con capacidad de mantener ese despliegue durante al menos un año, contando además, con los elementos marítimos y aéreos necesarios. Esta Fuerza de Reacción Rápida Europea deberá ser capaz de cumplimentar las misiones denominadas «Petersberg» (nombre del castillo en Bonn donde tuvo lugar la Declaración de la UEO en 1992, donde se definieron esas misiones), y que comprenden: mantenimiento de la paz, imposición de la situación de paz, gestión de crisis y ayuda humanitaria.

En uno de los anexos, el Consejo Europeo en la Cumbre de Helsinki trata la cuestión de la industria europea de defensa, haciendo constar que: «los Estados miembros han acogido con satisfacción los recientes avances en materia de reestructuración de las industrias europeas de defensa que constituyen un importante paso adelante y contribuyen a fortalecer la base industrial y tecnológica de la defensa europea",

La Cumbre de Helsinki, constituye un hito histórico de reafirmación de la CESDP y donde el aparato institucional de dicha defensa común, junto con los objetivos y calendarios, quedan perfectamente diseñados.

En esta línea, el 20 de Noviembre del 2000, tuvo lugar en Bruselas la primera Conferencia sobre el Compromiso de Capacidades, en la que los Ministros de Defensa de la Unión Europea reafirman su compromiso (formulado en Helsinki) y especifican las respectivas capacidades nacionales con la que pretenden contribuir a la formación de la fuerza conjunta. Se pretende que, en líneas generales, los objetivos establecidos se alcancen en el 2003.

La Segunda Conferencia sobre las mejoras y progreso de las Capacidades, deberá tener lugar el 19 y 20 de Noviembre de 2001, en la que los Ministros de Defensa de la UE analizarán el cumplimento de los compromisos para alcanzar el «Headline Goal» de formación de la fuerza con- 
La industria aeroespacial: un modelo...

junta de 60.000 hombres, con los requisitos de disponibilidad y despliegue, para el cumplimiento de las misiones Petersberg.

El resultado de esta Conferencia servirá para sustanciar la Cumbre Europea del 14-15 de Diciembre del 2001 en Laeken (Bélgica), en la que los Ministros podrán declarar formalmente que la fuerza conjunta de reacción rápida está operativa.

Quedan evidentemente muchas lagunas por rellenar, pero también en este camino se está avanzando muy decididamente para alcanzar los Objetivos (Headline Goals) que se definieron en Helsinki.

\section{Conclusiones}

Desde la famosa «Ultima Cena» en 1993, en la que el Secretario de Defensa de Estados Unidos instó a los dirigentes de las principales empresas aerospaciales americanas a dimensionarse para adaptarse a un futuro mucho más austero, hasta el día de hoy en los albores del siglo XXI, se ha producido, evidentemente, una verdadera revolución en el sector aerospacial en ambos continentes pero desde una perspectiva diferente:

En Estados Unidos para posicionarse ante el mundo como líder indiscutible y, al mismo tiempo, para consolidarse en su mercado nacional y hacer frente a un drástico cambio de la amenaza y unos recursos más escasos.

En Europa, en una primera instancia, para sobrevivir frente al gigante americano y no dejar reducida su industria aerospacial a un mero papel subsidiario y, en segundo lugar, prácticamente de forma simultánea, para empezar a salir del letargo bajo el amparo de la Alianza Atlántica y tomar conciencia de su propia identidad de seguridad y defensa.

Los movimientos en ambos continentes han tenido como principales actores a las industrias aerospacial y de electrónica de defensa, por ser las piezas clave en el desarrollo y producción de sistemas de armas críticos, de alto contenido tecnológico y con costes de desarrollo crecientes, asociados a su propia complejidad.

El impulso en ambos sectores industriales para encontrar la adecuada dimensión ha venido propiciado, a su vez, por el enorme auge experimentado en la aviación comercial, generadora de una inmensa infraestructura aérea y, por otro lado, por lo que ha venido a denominarse, «La Revolución de los Asuntos Militares» (Revolution of Military Affairs: RMA), resultado de la necesidad de generación proceso y control de un cada vez mayor volumen de información y, como consecuencia, de la integración de todos los sistemas con ella relacionados (C4ISR). 
La facilidad con la que el proceso se ha desarrollado en los Estados Unidos, ha venido dada por la homogeneidad del propio contexto; un solo país y, por tanto, una única soberanía que defender, un solo cuerpo legal $\mathrm{y}$ administrativo $\mathrm{y}$ un verdadero impulso a las empresas propiciado $\mathrm{y}$ apoyado -y en gran parte financiado- por el propio Gobierno.

El proceso seguido en Europa ha sido -y es- sin embargo, muy otro. No existe un espacio común europeo; en el conjunto de naciones de la Unión Europea existe un arraigado sentido del principio de soberanía en cada una de ellas; existen cuerpos legales y administrativos distintos, y las industrias han sido en gran medida de propiedad estatal y, aún todavía, algunas están sujetas a un cierto control de los Estados.

Con todo ello, se pueden aventurar las primeras conclusiones, por supuesto discutibles, para ambos procesos:

En Estados Unidos, tomando como modelo -y patente realidad- la industria aerospacial, se han cumplido los objetivos perseguidos y, salvo pequeños y posteriores ajustes, no parece posible llegar mucho más allá en la consolidación-integración industrial, salvo caer en situaciones no deseables, de verdadero monopolio.

En Europa se ha conseguido un primer y muy importante objetivo: sobrevivir en el entorno internacional y en el propio europeo contrarrestando, de momento, la amenaza americana. Para ello, la industria aeroespacial ha tenido que tomar la delantera a sus propios Gobiernos (¿o quizá con ciertas directrices y con su aquiescencia?), saltando por encima de obstáculos legales políticos, etc., en aras de su propia supervivencia, quedando dichos aspectos en gran parte sin resolver, solamente «hilvanados», que obligará a una mayor celeridad en la búsqueda de acuerdos y soluciones para homogeneizar, regularizar y simplificar las relaciones entre la diversidad de cuerpos legales. El importante componente político que siempre ha estado, o bien presente, o en la trastienda de todo el proceso de privatizaciones, reestructuración e integración, denota claramente la voluntad de los Gobiernos de ir cumpliendo todas las etapas que consoliden esos objetivos.

Nos encontramos pues, en la actualidad, con la siguiente perspectiva:

Una clara situación de duopolio en Estados Unidos con los dos grandes: Boeing, con preponderancia clara en la aviación comercial; y Lockheed Martin, con una mayor componente en la industria de defensa.

Una situación similar de duopolio en Europa, con otros dos grandes : EADS también con indudable preponderancia en aviación comercial (con Airbus Integrated Company donde BAeS participa con el 20\%); y BAeS, con el mayor peso en el sector defensa. Quedan sin embargo importantes piezas que colocar en el tablero europeo: Thomson CSF, el líder (por en- 
cima de BAeS) en electrónica de defensa, especialmente tras su alianza con Alcatel; Dassault Aviation en aviación de combate y, finalmente, Finmeccanica con su estrategia de «Joint Ventures». Estas piezas tendrán obligatoriamente que moverse para consolidar verdaderamente el siguiente paso del proceso de reestructuración.

Desde esta perspectiva y con todo este camino ya recorrido, la siguiente etapa parecía lógico pudiera encaminarse hacia la consecución de una gran integración transatlántica o hacia una fase intermedia de afianzamiento de las Joint Ventures o acuerdos de cooperación para programas específicos entre compañías aeroespaciales de uno y otro lado. Las dudas se despejaron y las directrices quedaron fijadas tras la reunión convocada y mantenida por el Subsecretario de Defensa de Estados Unidos (Deputy Secretary of Defence) John Hamre el pasado mes de Octubre con los Directores Nacionales de Armamento de Francia, Alemania, Reino Unido y Estados Unidos, así como con los líderes de la industria aeroespacial de dichos países, con el objeto de evaluar y debatir la actual situación y futuros pasos en la posible reestructuracón transatlántica.

El mensaje quedó perfectamente claro para todos los asistentes: Washington no acepta ni propicia ningún tipo de fusión transatlántica a gran escala entre empresas aeroespaciales, ni siquiera a medio plazo, por considerarlo prematuro por diversas razones, entre las que se adujeron como principales: una disminución de la competencia con un incremento de la situación de monopolio y la carencia de una normativa común reguladora, USA/Unión Europea, de todos los aspectos del tráfico industrial. La principal razón de carácter político-estratégico, aunque evidentemente no mencionada, quedó en el ánimo de todos.

Por tanto, solamente serían bienvenidas y amparadas todo tipo de Joint Ventures o alianzas limitadas a la consecución de objetivos concretos o a la realización de programas.

Con todos estos ingredientes y tomando en consideración los recientes acontecimientos de clara repercusión mundial, se podrían aventurar unas ideas de su impacto en la industria aeroespacial. Es evidente que tras el atentado terrorista el pasado 11 de Septiembre en Nueva York, el segmento de la aviación comercial está sufriendo una profunda crisis a nivel mundial. No obstante, es previsible que el duopolio Boeing-Airbus (EADS) se mantenga en el reparto del mercado global con ciertas ventajas coyunturales de uno u otro lado.

El sector defensa, por su carácter cíclico se verá sin embargo reforzado a ambos lados del Atlántico con la violenta aparición de una nueva amenaza -que hasta ahora ha estado en cierto modo larvada- de conse- 
cuencias imprevisibles. El balance USA/Unión Europea en este sector en sus aspectos principales es el siguiente:

En el segmento de aviación de transporte militar, una de las acusadas carencias en el conjunto de la Unión Europea, ésta se juega su futuro en dicho segmento, a menos que se haga realidad el programa del gran avión de transporte A-400M .

En el segmento de la aviación de combate, tras el lanzamiento y adjudicación del contrato del avión JSF (Joint Strike Fighter) a Lockheed Martin, la industria Europea está seriamente amenazada. El avance tecnológico que supone este avión (en especial la incorporación de tecnología «stealth"), el competitivo coste de adquisición y la polivalencia para todos los usuarios (Fuerzas Aéreas, Fuerzas Navales, etc.), va a producir una inundación de los mercados, sumada a la producida por la salida de servicio de los aviones de combate de la generación anterior (en especial miles de F-16) y que sin duda, todavía, cubrirán las necesidades de multitud de países. O Europa hace sus deberes, consolida sus fuerzas en este segmento y sale a la arena, o después del Eurofighter y el Rafale, las posibilidades van a ser muy escasas.

La industria de la electrónica de defensa, con la actual necesidad de elementos para la guerra de la información ("Information Warfare") y su integración en un sistema de sistemas (C4ISR), merece el comentario del auge exponencial que ha experimentado y el de su previsible y creciente continuidad por la multiplicidad de sus aplicaciones y por la potenciación y asequibilidad proporcionada por desarrollos comerciales de muy alta tecnología. En este campo, el desequilibrio tecnológico de Europa, respecto a Estados Unidos es más que considerable.

Se puede concluir afirmando lo evidente: Estados Unidos y Europa se han adaptado al nuevo orden mundial; los primeros con gran ventaja en el tiempo y con una gran solidez; la segunda, aunque mucho mas tarde y por consideraciones de identidad y de supervivencia, ha dado sin embargo un paso de gigante. En ambos casos la industria aerospacial ha llevado el liderazgo y ha servido de modelo.

Y ahora suponiendo que Europa remate la tarea, con verdadera voluntad política y consolide su posición, cabe preguntarse hacia donde vamos, si hacia una «fortaleza Europa» frente a una «fortaleza USA», o hacia una verdadera reestructuración-integración trasatlántica. Parece ser que, esto último, está de momento vetado.

Y por último: ¿Está seguro el orden mundial actualmente alcanzado?. Las previsiones y decisiones que se tomen a corto plazo en el mundo occidental, serán probablemente la clave del futuro. 
Reestructuración del sector aerospacial

Reacción dinámica de la industria americana



\section{Anexo 2}

\section{SOCIEDADES CONJUNTAS («JOINT VENTURES»)}

Noviembre 1990 Matra Marconi Space (MMS):

Matra y GEC Marconi se unen (51\% Matra, 49\%

Marconi)

Enero 1992 Eurocopter:

Se constituye con las divisiones de helicópteros de Aerospatiale MBB/DASA

Enero 1995 Bayer-Chemie:

Constituida por DASA y Thomson CSF al 50\% para Sistemas de propulsión de misiles.

Enero 1995 TDA:

Constituida por DASA y Thomson CSF al 50\% para Sistemas de cabezas de guerra de misiles.

Agosto 1996 Matra BAe Dynamics (MBD):

Matra y BAe unen sus actividades de misiles al $50 \%$ de participación.

Octubre 1997 MBD adquiere el 30\% de LFK (DASA).

Octubre 1997 Alcatel Space:

Thomson CSF y Alcatel Satélites se unen en un $50 \%-50 \%$.

Febrero 1998 Westland y Agusta Finmeccanica forman una Joint Venture 50/50 (Helicópteros).

Julio 1998 Alenia Marconi Systems (AMS):

GEC Marconi (UK) y Finmeccanica constituyen una Joint Venture 50/50 para desarrollo de radares, sistemas de mando y control y simulación.

Mayo 1999 Thomson-CSF y Eurocopter constituyen una Joint Venture para entrenamiento de pilotos de Helicópteros.

Octubre 1999 Sociedad Europea de Misiles:

AMS se integra en Matra BAe Dynamics: el 20 de Octubre, Aerospatiale Matra, BAe y Finmeccanica firmaron el acuerdo para la formación de una Sociedad común que integrará las actividades de misiles y sistemas de misiles.

Octubre 1999 Astrium:

DASA y la Joint Venture Franco-Británica MMS integran sus actividades espaciales y deciden fundar la Compañía espacial Astrium. 

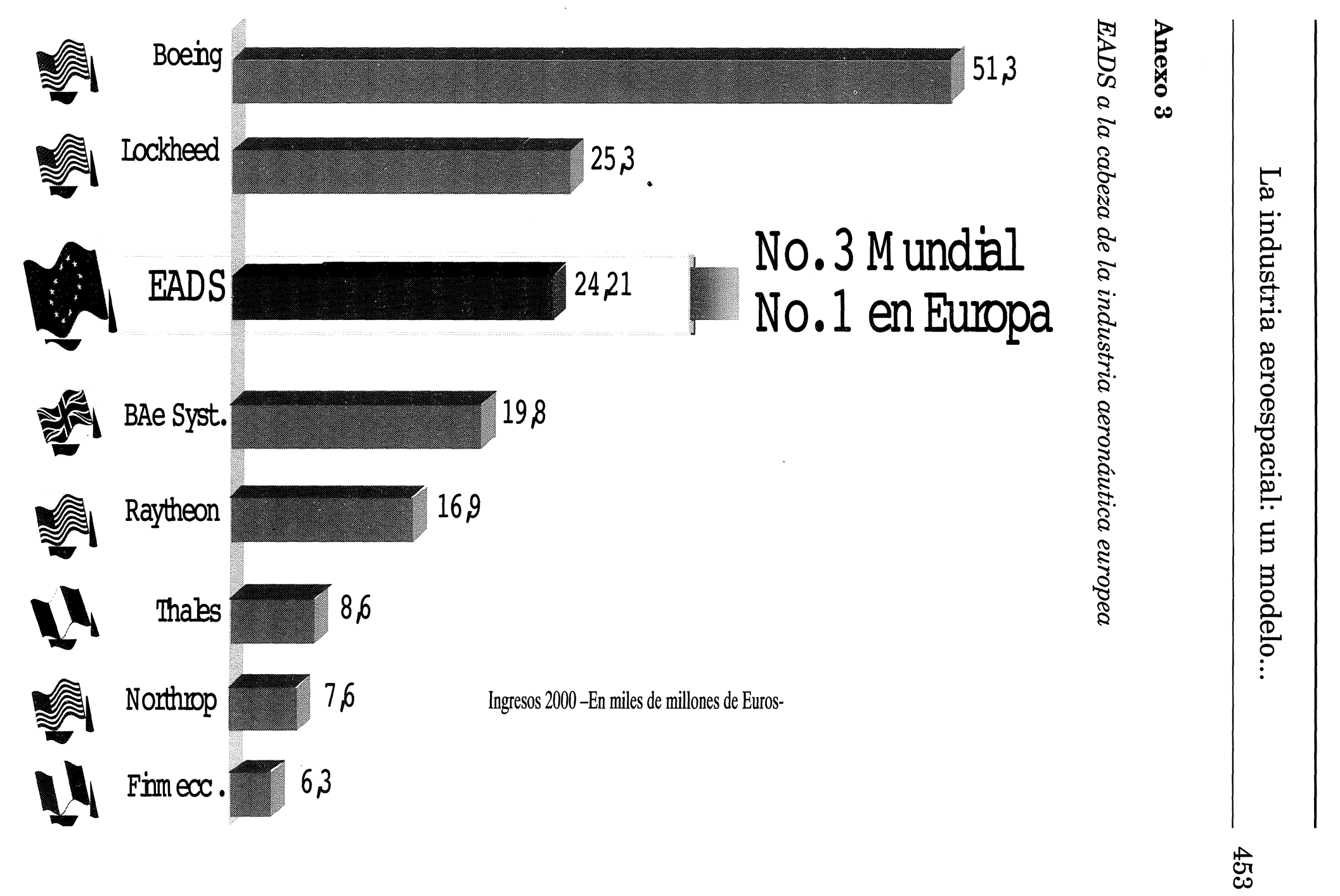


\section{Santiago San Antonio Copero}

\section{Anexo 4}

Posición de liderazgo de EADS en todos los segmentos

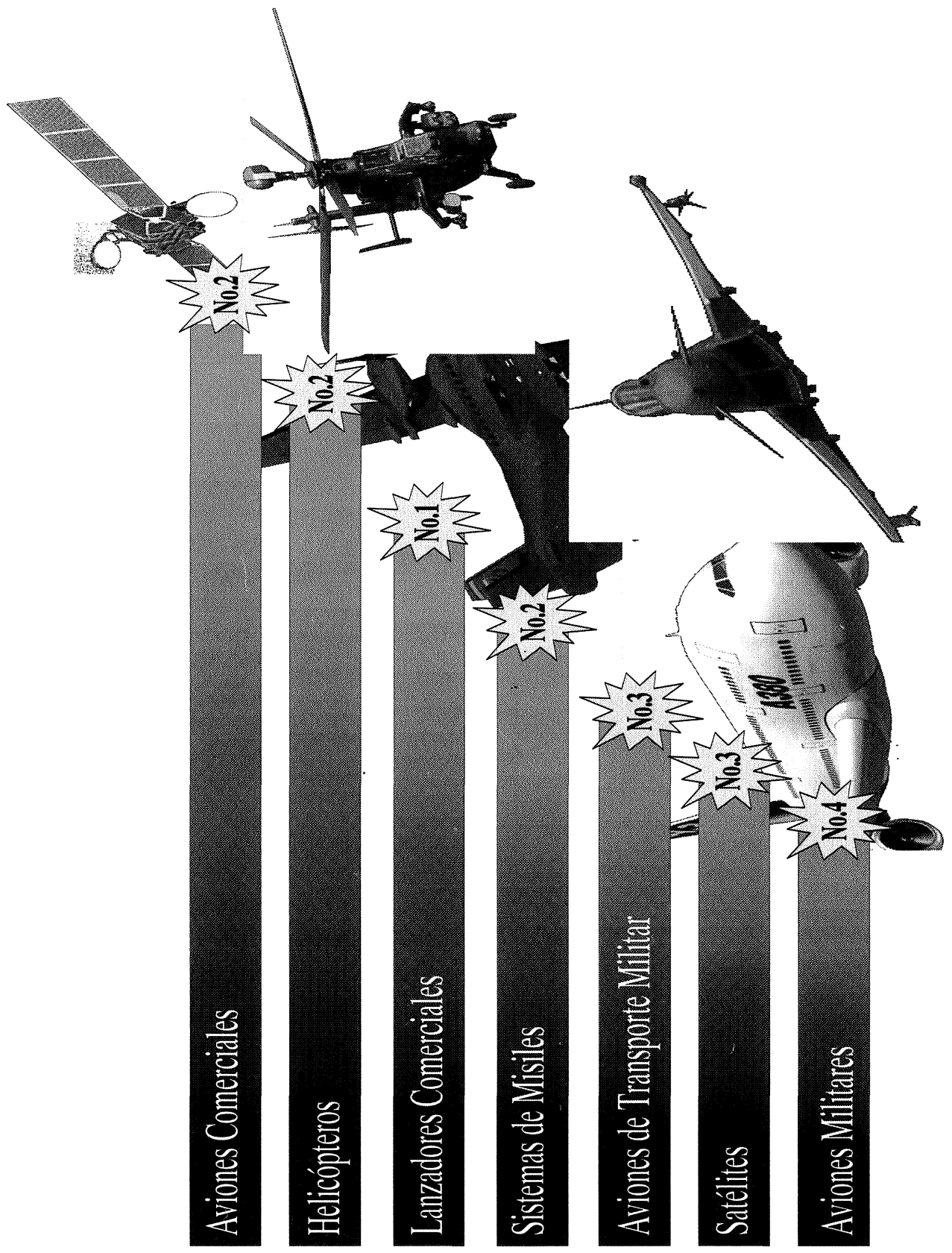




\section{Bibliografía}

Documentación consultada:

\section{Boletines de Información del CESEDEN}

Núm. 261 Año 1999

Núm. 262 Año 1999

Núm. 263 Año 2000

Núm. 264 Año 2000

\section{Documentos}

- Documento interno de fusión entre Aerospatiale-Matra, Daimler Chrysler Aerospace y Construcciones Aeronáuticas, S.A.

- Documento informativo "Daimler Chrysler Aerospace AG in Retrospect».

- Documento informativo sobre estructura de Aerospatiale-Matra.

- Documento informativo sobre el Grupo Lagardere.

- Documento sobre la creación del Grupo Airbus SAS (Amsterdam Julio 2001).

- Chaillot Paper 40. Institute for Security Studies of WEU 2000. Julio 2000.

- Chaillot Paper 43. Institute for Security Studies of WEV 2000. Noviembre 2000.

- Conferencia del Secretario de Defensa USA, William S. Cohen al Congreso alemán, en Hamburgo. 1 de Diciembre 1999.

- Tratado de Amsterdam. Firmado al 2 de Octubre 1977

- White Paper on European Union Arms Exports. In response to the European Parliament request. 15 Mayo 1997.

- MoU entre Alemania, Francia y Reino Unido, sobre «The Restructuring of the European Defence Industrial Base», 19 Enero 1998.

- Declaración conjunta de los Ministros de Defensa de Francia, Alemania, Italia España y Reino Unido, sobre la Reestructuración de la Industria de Defensa. 20 de Abril 1998.

- Carta de Intenciones (LoI) entre los Ministros de Defensa de Francia, Alemania, Italia, España, Suecia y Reino Unido, relativa a las «Medidas para facilitar la Reestructuración de la Industria de Defensa Europea», 6 de Julio 1998.

- Acuerdo Marco entre Alemania, España, Italia, Suecia y Reino Unido, relativo a las» Medidas encaminadas a facilitar la Reestructuración y Funcionamiento de la Industria Europea de Defensa. 27 de Julio de 2000

\section{Revistas}

- Military Technology:

- Vol. XXIII Issue 41999

- Vol. XXIII Issue 111999

- Vol. XXV Issue $2 \quad 2001$

- Vol. XXV Issue 52001

- Vol. XXV Issue 82001 


\section{6}

\section{Santiago San Antonio Copero}

- Vol. XXV Issue 92001

- Armed Forces Journal: Agosto 1998

- Defense News: Octubre 15-21, 2001 